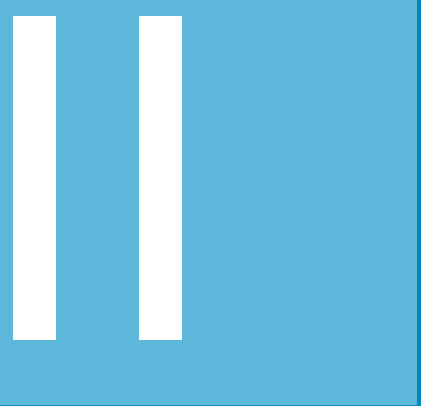

\title{
EL CURRÍCULO EN UNA UNIVERSIDAD ADVENTISTA
}

\section{The Curriculum in an Adventist University}

\section{Raquel B. de Korniejczuk}

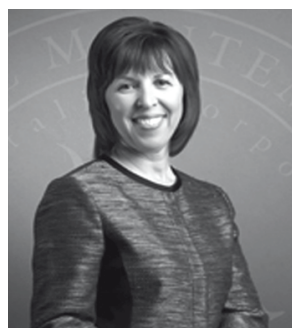

Licenciada en Letras por la Universidad Católica de Santa Fe. Doctora en Educación en Currículo y Didáctica por la Andrews University. Actualmente se desempeña como Vicerrectora académica en la Universidad de Montemorelos, México. Asimismo, realizó actividades de docencia en diversos posgrados organizados por dicha universidad. Ha publicado numerosos artículos en revistas nacionales y extranjeras, es ponente y conferenciante a nivel internacional. 
Raquel B. de Korniejczuk AÑO II •NÚMERO 1 • p. 21 - 30

\section{Resumen}

Se muestra la necesidad de un currículo en una institución adventista donde los estudiantes al concluir sus estudios tengan una cosmovisión cristiana de su vida y profesión. Se presenta los elementos de un currículo desde la perspectiva de la educación adventista; los elementos esenciales de la educación adventista concluyendo que el currículo de una institución es clave en el cumplimiento de este propósito porque cada una de las experiencias de aprendizaje por las que pasa un estudiante hacen un impacto que, en su conjunto, determinan el futuro de un profesional en cuanto a cómo ve su profesión, su fe, su familia y su misión.

Palabras clave: Currículo, educación, perfil, cosmovisión.

\section{Abstract}

In this work is showed the need of a curriculum of a Adventist Institution, where each student can have a Christian worldview about their life and field by concluding their studies. So, in this work is presented the curriculum- elements, the essential elements of the Adventist education so that the curriculum of an Institution can be considered very important in the fulfillment of the desired goals. On the other hand, the experts in Education field, points out that each students 'experiences and in its totality will do a great impact in their life and determine their future as a professional and how they can see their profession, their faith, their family and their mission.

Keywords: Curriculum, education, profile, worldview. 


\section{Introducción}

Cuando la Universidad Harvard revisó por última vez su currículo, una de las discusiones mayores estuvo en torno a la inclusión de la religión en su área de formación general. Lisa Miller dice que los docentes de esa universidad "no se podían poner de acuerdo en quién debía enseñarla, cómo debía ser enseñada y cuánto valor se le daría comparado con la Economía, la Biología, la Literatura y otras materias que se consideran vitales para la educación universitaria" (Miller, 2010, p. 45).

Después de mucha discusión, el currículo revisado de Harvard, que se comenzó a implementar en agosto del 2009 determina que un "estudiante tiene que tomar un curso en cada una de ocho categorías, incluyendo dos en ciencia y uno en matemáticas. Tiene que tomar una materia en la categoría Cultura y Creencia, que incluye cursos de religión pero también fotografía, mitología y literatura" (p. 45). Eso significa que un alumno de Harvard puede graduarse sin haber tomado ninguna materia que considera cómo las personas se definen en relación con Dios.

Es indudable que Harvard, desde sus orígenes en 1636 como una institución cristiana, destinada fundamentalmente a formar ministros, basada en el lema Christo et Ecclesia (por Cristo y la Iglesia) ha transitado un camino hacia la secularización, incluso cambiando su logo en 1843 por el de Veritas (Verdad) y finalmente arrinconando el estudio de Dios de tal manera que actualmente ni siquiera tiene un departamento de Religión.

Al mirar a las instituciones adventistas de educación superior, un educador puede preguntarse si las universidades adventistas en la actualidad están recorriendo el mismo camino hacia la secularización. Y la pregunta vital que subyace es ¿cómo debe estar diseñado un currículo en una institución adventista para que los estudiantes al concluir sus estudios tengan una cosmovisión cristiana de su vida y de su profesión, sean leales a su fe y cumplan con la misión de Cristo?

Benne (2001), quien hizo una investigación para determinar cuáles eran los elementos claves para que las universidades cristianas mantengan su $\mathrm{fe}$, señala nueve elementos, siete de ellos relacionados directamente con el currículo: la relevancia pública de la visión, la relevancia del departamento de teología, los cursos de teología requeridos, la asistencia a los cultos requeridos, los códigos de comportamiento morales y otros usos y costumbres. Las instituciones que mantienen estos elementos según su visión y objetivos son las que no transitan por la secularización. 
Raquel B. de Korniejczuk

La historia de las instituciones adventistas de educación superior muestra que el currículo ha sido un campo de batalla. Elena de White entre 1874 y 1881 envió numerosos mensajes a los maestros, administradores y estudiantes del Colegio Battle Creek, animándolos a diseñar e implementar un currículo de acuerdo con el modelo de Dios. Los administradores y maestros querían conformarse con el currículo que en sus días tenían las instituciones de educación superior y ofrecer de modo opcional los elementos distintivos de la educación cristiana. Unos años después, en 1884, cuando se inició el Colegio Avondale, ella, que había acompañado el proyecto desde sus inicios, mostró su beneplácito porque el modelo educativo tenía los elementos que Dios había incluido al elaborar un plan educativo para la humanidad. La diferencia entre estos dos modelos educativos está en la presencia o ausencia de los elementos esenciales de un currículo adventista.

\section{Los elementos de un currículo}

Aunque la literatura de la especialidad define el currículo de muchas maneras, en este artículo se entenderá como todas las actividades planificadas de una institución educativa: esto incluye el currículo formal, es decir, los planes de estudios y el currículo informal, que comprende todas las actividades organizadas por la institución, pero que no son requisito obligatorio para que un estudiante tenga un título.

Cuando una institución desarrolla su propio currículo tiene un modelo educativo que la distingue, y es entonces cuando puede hacer un impacto coherente en la formación de sus estudiantes.

Aunque hay muchos modelos de conformación y desarrollo del currículo, todos comparten algunos elementos que siempre están presentes. Cuando se consideran estos elementos desde la perspectiva de la educación adventista, se va conformando un modelo educativo.

a. El fundamento filosófico. Un currículo no se desarrolla en el vacío. No existe algo así como neutralidad filosófica en la educación. Todo modelo responde a una concepción filosófica que orienta y da sentido a la actividad educativa de la institución. Este fundamento filosófico principalmente determina quién es el maestro, quién es el alumno, cuáles son las materias más importantes en un currículo y cuáles son las estrategias de aprendizaje más valiosas. Estos elementos son claves en la concepción básica de una escuela. 
b. El contexto. Una institución educativa sirve a públicos y está ubicada en un ambiente físico y cultural. Aunque el mundo contemporáneo está muy globalizado y hay tendencias internacionales que influyen en contenidos y estrategias educativas, existen otros factores externos e internos a la institución que conforman el contexto.

Entre los factores externos más importantes que influyen en el contexto educativo están las fuerzas del mercado laboral, las políticas y acciones gubernamentales, las tendencias de la sociedad y los organismos que rigen el estudio de las distintas áreas académicas. En la educación adventista, estos factores deben ser analizados a la luz de la filosofía de la institución.

Además de estas influencias externas, la organización, recursos y oferta académica de una institución, son fuerzas que internamente se interrelacionan para determinar un currículo específico.

c. El propósito. Si algo tienen en común las instituciones de educación adventista, además de su fundamento filosófico, es su propósito que se puede resumir en la conocida frase "Educar es redimir". Es que el fin primario de la educación adventista es la redención, que consiste en que el educando acepte a Cristo como su Salvador personal, y permita que Él restaure la imagen de Dios en el hombre, ya que ha estado desdibujada por los efectos del pecado. El fin último de la educación adventista es el servicio abnegado. Un egresado de una institución adventista es un profesional que se espera esté comprometido con la misión de Cristo, y se concrete en una vida profesional, personal y familiar de constante servicio generoso y desinteresado a los demás. El propósito determina, en gran manera, la selección de experiencias de aprendizaje.

d. Los contenidos y su secuencia. En un sentido, un currículo se parece a la elaboración de una receta de cocina. Se seleccionan los ingredientes, la cantidad de cada uno de ellos, y el orden y la manera cómo ser van a incorporar y tratar durante el proceso de preparación. Los ingredientes son los contenidos. Toda institución toma decisiones cruciales en cuanto a qué es lo más valioso para ser aprendido y cuánto tiempo y esfuerzo se debe poner en cada uno de los contenidos. Así como el éxito de una receta de cocina depende de la selección de los ingredientes, su cantidad y el orden de su incorporación, en un currí- 
Raquel B. de Korniejczuk

culo son muy importantes la selección de experiencias de aprendizaje, su nivel de profundidad y cuándo se deben aprender. Los elementos esenciales de la educación adventista deben ser los componentes básicos de un currículo apropiado.

e. Aprendices y maestros. El proceso educativo ocurre en la relación entre el maestro y el alumno. Para los docentes adventistas, el ejemplo de Cristo como maestro es fundamental. Su tarea es la de hacer discípulos. El trabajo de formar discípulos es mucho más amplio y profundo que la tarea simple de un docente que da una clase y luego se va. Comprende una relación muy cercana de mentor y aconsejado. Además la formación de discípulos implica que la misión, el destino y el objetivo del trabajo están fuera de las puertas de la universidad, y allí, afuera, es donde hay problemas que resolver. Para ello, el aporte del docente es crucial en la investigación. Y la tarea del aprendiz, del discípulo, es la de seguir a su maestro y convertirse en un multiplicador de la resolución de los problemas fuera de la universidad.

f. Procesos y recursos de aprendizaje. La selección de las estrategias y recursos de aprendizaje es tan importante como la selección de los contenidos. Es que la formación de profesionales que sepan pensar críticamente, discernir entre lo que está bien y lo que está mal y sepan tomar decisiones sabias libremente depende más de la manera cómo aprende que de los contenidos en sí. La iglesia adventista, desde sus orígenes, se ha destacado por tener miembros inquisitivos, que buscan por sí mismos la verdad. Este espíritu de búsqueda de la verdad debe prevalecer en los procesos de aprendizaje y los recursos deben promover la conformación de una cosmovisión cristiana de la vida y del destino, así como una búsqueda consciente de la verdad.

g. Evaluación. La evaluación requiere comparar lo realizado con una medida. Es como mirarse en un espejo. El espejo debe ser las expectativas de la iglesia para la educación superior. La declaración de filosofía de la educación, que fue revisada y publicada hace unos años (2001) provee de un perfil deseado del egresado de una institución superior. 


\section{TABLA 1}

Los estudiantes al finalizar sus estudios universitarios deberían:

- Haber tenido la oportunidad de entregarse a Dios y, como consecuencia, vivir una vida de acuerdo con su voluntad, apoyando el mensaje y la misión de la Iglesia Adventista del Séptimo Día.

- Ser capaces de ejercer el pensamiento crítico, practicar la mayordomía de sus talentos, manifestar creatividad, aprecio por la belleza, respeto por la naturaleza y destreza en la comunicación y la investigación -cualidades que los capacitarán para ejercer su vocación y continuar aprendiendo a lo largo de su vida.

- Revelar sensibilidad en las relaciones interpersonales e interés respetuoso por el bienestar de los demás, manifestando madurez para el matrimonio y la vida familiar, para contribuir al mejoramiento de la comunidad y participar activamente en la fraternidad adventista.

- Practicar hábitos de vida que demuestren un compromiso con las prácticas de la buena salud, esenciales para vivir una vida plena. Esto incluye el uso cuidadoso del tiempo y la selección juiciosa de la música, los medios de comunicación y otras formas de entretenimiento.

- Responder al llamado de Dios en la elección y el ejercicio de una carrera o profesión, apoyando mediante ella la misión mundial adventista y contribuyendo al desarrollo de una sociedad libre, justa y productiva.

Fuente: Tomado de la Declaración de Filosofía de la Educación Adventista del Séptimo Día, 2001.

Las características de este perfil pueden ser utilizadas como elementos de control para una evaluación del currículo.

\section{Los elementos esenciales de la educación adventista}

La educación adventista comparte muchas de sus características con otros modelos de educación cristiana (ver Hughes, 1997; Benne 2001; Liftin, 2004; Ream, Beaty and Lion, 2004). Sin embargo, a partir de un estudio cuidadoso de los escritos de Elena de White, se pueden espigar elementos esenciales de la educación, que también aparecen en los antiguos modelos de escuelas que describe la Biblia como la escuela del Edén y la escuela de los 
Raquel B. de Korniejczuk

profetas. Estos elementos esenciales deben formar parte tanto de la educación formal como de la no formal, para que el estudiante tenga la oportunidad de desempeñarse con maestría en cada uno de ellos.

a. Relación con Dios. Ya que el fin primario de la educación adventista es que el alumno tenga un encuentro salvador con Cristo, la relación con Dios es un elemento esencial. El desarrollo de esta relación con Dios debe abarcar todos los aspectos del desarrollo humano: en el aspecto intelectual, el estudio de la Biblia, la Palabra de Dios provee de un desarrollo intelectual sin par; en el aspecto relacional, el servicio por los demás es una manera de responder con hechos a una relación con Dios, lo que representa el fin último de la educación adventista. Así, es deber de la educación adventista proveer espacios curriculares para un estudio concienzudo y profundo de la Biblia y para el servicio abnegado por los más necesitados. Esto debe ir acompañado de una gran variedad de experiencias que atiendan las vocaciones, necesidades y gustos de los estudiantes.

b. Capacitación profesional. En la educación adventista la capacitación profesional es más que una capacitación para el desempeño laboral; es una capacitación para cumplir la misión de Cristo. La preparación profesional es un medio para que el egresado cumpla la misión de su vida. Por lo tanto, el desarrollo de la capacitación profesional debe dar al estudiante herramientas y experiencias para el cumplimiento de esta misión.

c. Preparación para la vida. En general, las universidades se abocan a la capacitación profesional, pero la vida misma es mucho más que eso. Además, enseñanzas que hasta hace pocos años estaban circunscritas a la familia, han desaparecido como tales. Entre los asuntos cruciales que un profesional requiere para tener éxito en la vida están la salud, la familia, el trabajo y el liderazgo.

La iglesia adventista tiene un mensaje claro sobre el cuidado de la salud, tanto preventivo como terapéutico. Los hábitos del cuidado de la salud (alimentación, ejercicio, descanso, etc.) deben estar presentes y ser incorporados en el currículo institucional.

Los años universitarios y los inmediatamente posteriores a la adquisición de un título universitario constituyen el período cuando un joven decide con quién va a formar una familia y cómo va a educar a los hijos cuando lleguen. Es por eso que el currículo universitario debe incluir experiencias 
de aprendizaje que ayuden al estudiante a tomar decisiones sabias cuando sea el momento oportuno.

Una de las tendencias generalizadas entre los jóvenes actualmente es la falta de hábitos y herramientas para el trabajo. Mientras tienen una capacitación universitaria intelectual y carecen de las habilidades y las actitudes necesarias para tener éxito en cualquier empresa laboral. La universidad debe proveer oportunidades para la adquisición de estas herramientas importantes.

d. Perspectiva del arte y la cultura. Los medios, el entretenimiento, las manifestaciones culturales y artísticas son muy importantes en el tiempo en que vivimos. Parte de la formación de una cosmovisión cristiana consiste en la selección de estas manifestaciones de tal manera que fortalezcan el carácter de la persona. Un currículo debe tener especial cuidado en desarrollar en el estudiante un conjunto de criterios que responden a una axiología cristiana en la selección de esas manifestaciones.

\section{A modo de conclusión}

Las instituciones educativas adventistas tienen un compromiso con la iglesia y con Dios en la formación de los líderes de las próximas generaciones para el cumplimiento de la misión de Cristo. El currículo de una institución es clave en el cumplimiento de este propósito porque cada una de las experiencias de aprendizaje por las que pasa un estudiante hacen un impacto que, en su conjunto, determinan el futuro de un profesional en cuanto a cómo ven su profesión, su fe, su familia, su misión.

Como educadores adventistas debemos preguntarnos constantemente qué es lo más valioso para ser enseñado y aprendido y cómo es la mejor forma de aprender para que el resultado sea hombres y mujeres con un desarrollo destacado en la facultad de pensar y hacer.

Raquel B. de Korniejczuk 
Raquel B. de Korniejczuk

\section{Referencias}

Benne, R. (2001). Quality with soul: How six premier collages and universities keep faith with their religious traditions. Grand Rapids, MI: Eerdmans.

Hughes, R. T. Y Adrian, W. B. (Eds.). (1997). Models for Christian higher education: Strategies for success in the twenty-first Century. Grand Rapids, MI: Eerdmans.

Liftin, D. (2004). Conceiving the Christian collage. Grand Rapids, MI: Eerdmans.

Miller, L. (2010, 22 de febrero). Harvard's Crisis of Faith: Can a secular university embrace religión without sacrificing its soul? Newsweek, p. 44-48.

Ream, T.C., Beaty, M. y Lion, L. (2004). Faith and learning: Toward a typology of faculty views at religious research universities. Christian Higher Education, 3,4, p. 349-372. 